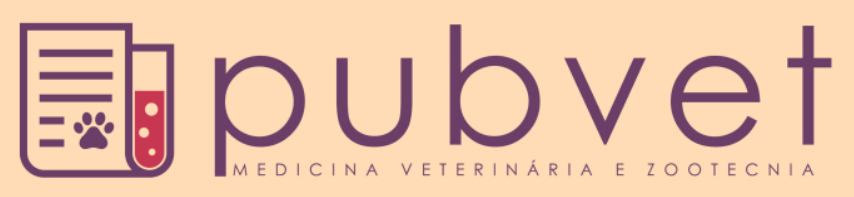

HTTP://DX.DOI.ORG/10.22256/PUBVET.V11N9.913-916

\title{
Saculite anal polimicrobiana em cão com hipotireoidismo: Relato de caso
}

\author{
Fernanda Vieira Henrique ${ }^{1 *}$, Lilianne Marinho dos Santos ${ }^{2}$, Carla Lauise Rodrigues \\ Menezes Pimenta ${ }^{1}$, Pedro Gustavo Santos Nóbrega ${ }^{3}$, Rosileide dos Santos Caneiro ${ }^{4}$, \\ Felício Garino Júnior ${ }^{5}$
}

\footnotetext{
${ }^{1}$ Médica Veterinária, doutoranda do Programa de Pós-Graduação em Medicina Veterinária (PPGMV), Universidade Federal de Campina Grande (UFCG), Patos, Paraíba (PB), Brasil.E-mail: carlalauise@ hotmail.com

${ }^{2}$ Médica Veterinária, mestranda do PPGMV, UFCG, Patos, PB, Brasil. E-mail: liliannemarinho@hotmail.com

${ }^{3}$ Médico Veterinário, Residente de Clinica Cirúrgica de Animais de Companhia na Universidade Federal do Semi-Árido (UFERSA), Mossoró, Rio Grande do Norte, Brasil. E-mail: pedro.gustavo_vet@hotmail.com

${ }^{4}$ Médica Veterinária, Clínica médica de pequenos animais, UFCG, Patos, PB, Brasil. E-mail: rosileide carneiro@yahoo.com

${ }^{5}$ Médico Veterinário, Doutor, Unidade Acadêmica de Medicina Veterinária, UFCG, Patos, PB, Brasil. E-mail: felício@gmail.com Autora para correspondência: nandinhavh@gmail.com.
}

RESUMO. Relata-se um caso de saculite anal em um canino de nove anos, macho, Cocker Spaniel, com hipotireoidismo. O animal apresentava constipação, havendo melhora após tratamento com levotiroxina. $\mathrm{O}$ animal voltou a ser atendido, onde se observou um aumento de volume dos sacos anais, além de secreção purulenta, sendo diagnosticada saculite. Realizou-se cultura microbiológica e antibiograma e o tratamento foi baseado em compressão manual e lavagem com solução fisiológica dos sacos anais e antibioticoterapia. A recuperação ocorreu após 10 dias de tratamento.

Palavras chave: Antibiograma, constipação, cultura microbiológica, saco anal

\section{Polymicrobial anal sacculitis in dog with hypothyroidism: Case report}

\begin{abstract}
We report a case of anal sacculitis in a canine, 9-year-old, male, Cocker Spaniel with hypothyroidism. The animal had constipation, with improvement after treatment with levothyroxine. The animal was again met, when there was an increase in volume of anal sacs, and purulent smelling, being diagnosed sacculitis. Held microbiological culture and antibiogram and the treatment was based on manual compression and washing with physiological solution of the anal sacs and systemic antibiotics and topical. The recovery occurred after 10 days of treatment.
\end{abstract}

Keywords: Antibiogram, constipation, microbiological culture, anal sac

\section{Saculitis anal polimicrobiana en perro con hipotiroidismo: Reporte de un caso}

RESUMEN. Se relata un caso de saculitis anal en un canino de nueve años, macho, Cocker Spaniel, con hipotiroidismo. El animal presentaba estreñimiento, habiendo mejoría después del tratamiento con levotiroxina. El animal volvió a ser atendido, cuándo se observó un aumento de volumen de los sacos anales, además de secreción purulenta, siendo diagnosticada saculitis. Se realizó una cultura microbiológica y antibiograma y el tratamiento se basó en compresión manual y lavado con solución fisiológica de las bolsas anales y antibioticoterapia. La recuperación se produjo después de 10 días de tratamiento.

Palabras clave: Antibiograma, estreñimiento, cultivo microbiológico, bolsa anal 


\section{Introdução}

Os sacos anais são estruturas modificadas anexas da pele e servem como reservatório de secreção pastosa e fétida produzida pelas glândulas sebáceas e hepatoides, contidas no seu epitélio escamoso de revestimento (Hedlund, 2008). A saculite anal é causada geralmente por uma infecção ou obstrução do ducto, que leva à infecção ou inflamação do saco anal. Acredita-se que ela esteja associada a afecções que promovem o esvaziamento inadequado dos sacos anais (Hedlund, 2008). Além disso, a permanência de fezes amolecidas nos sacos anais, tono muscular fraco em cães obesos e seborreia generalizada levando à retenção dos conteúdos do saco também podem estar associados à saculite anal. Não há predileção por idade ou sexo, porém, cães de raças pequenas e toys são mais acometidos (Aronson, $\underline{2007)}$.

Os sinais clínicos observados em caso de saculite são: dermatite aguda ou outras dermatoses; disquezia e constipação (Panciera, 1990); odor desagradável; presença de secreção purulenta contendo sangue; edema e eritema em volta da região dos sacos anais; pirexia; e sensibilidade dolorosa (Hedlund, 2008).

O diagnóstico sugestivo da doença do saco anal pode ser obtido apenas com o exame clínico e digital do reto, pois o saco anal se torna distendido e levemente dolorido, não sendo possível sua compressão facilmente (Hedlund, 2008).

Recomenda-se a cultura e antibiograma do material do saco anal, sendo que as bactérias mais comumente encontradas em casos de saculite são: Streptococcus faecalis, Clostridium perfringens, Escherichia coli, Proteus spp., Staphylococcus spp., micrococos e difteróides (Hedlund, 2008). O tratamento clínico consiste na compressão do saco anal, seguida de sondagem, canulação e infusão de uma preparação aquosa de antibiótico e/ou corticosteroide (Nelson and Couto, 2006).

O objetivo desse trabalho é relatar um caso de saculite anal polimicrobiana em um cão idoso acometido por hipotireoidismo.

\section{Relato de caso}

Um canino, macho, Cocker Spaniel, com nove anos de idade, foi atendido no Hospital Veterinário do Centro de Saúde e Tecnologia Rural (CSTR) da Universidade Federal de Campina Grande (UFCG) Campus de Patos/PB, apresentando constipação há quatro dias. O proprietário relatou que o animal tinha hipotireoidismo, mas a levotiroxina não era administrada há três semanas.

Foi recomendado o retorno imediato da levotiroxina conforme prescrição anterior $\mathrm{e}$ solicitada a dosagem de tiroxina ( $\mathrm{T}_{4}$ total), bem como hemograma. O resultado laboratorial revelou $0,93 \mathrm{mcg} / \mathrm{dL}$ de $\mathrm{T}_{4}$ total, e leucocitose por neutrofilia com desvio à esquerda regenerativo, respectivamente. Quarenta e oito horas após a administração da levotiroxina o animal voltou a defecar.

Dois meses após o primeiro atendimento o animal foi atendido em clínica particular apresentando sensibilidade dolorosa na região perianal, suspeitando-se de carcinoma e enterite. Foram prescritos antibioticoterapia e antiinflamatório, havendo melhora clínica. Vinte dias após, o animal retornou ao Hospital Veterinário apresentando sensibilidade dolorosa e um aumento de volume na região dos sacos anais. Foi realizada a compressão manual (Figura 1) destes observando-se uma secreção purulenta de odor fétido com presença de sangue. Foi colhido conteúdo do saco anal e realizados cultura microbiológica e antibiograma. $\mathrm{Na}$ cultura bacteriana cresceram Salmonela spp., Klebsiella spp. e Proteus spp; no antibiograma identificou-se sensibilidade à ampicilina. O diagnóstico foi de saculite bilateral. $\mathrm{O}$ tratamento incluiu antibioticoterapia sistêmica (ampicilina, 20 $\mathrm{mg} / \mathrm{kg}$, a cada oito horas, 10 dias) e tópica (pomada de cefoperazona/prednisona, a cada 12 horas, 10 dias). O animal retornou com 10 dias, havendo total recuperação deste.

\section{Discussão}

A principal queixa do proprietário ao trazer o animal pela primeira vez ao hospital veterinário foi a ausência de defecação há quatro dias. Um dos sinais clínicos do hipotireoidismo é a constipação associada a fezes secas, resultante do decréscimo do peristaltismo e do prolongamento do tempo de trânsito intestinal (Panciera, 1990), assim a constipação pode ter ocorrido devido ao hipotireoidismo, uma vez que após dois dias de tratamento com levotiroxina, o animal voltou a defecar. Por outro lado, sabe-se que a saculite está comumente associada a afecções que promovem o esvaziamento inadequado dos sacos anais, que normalmente deveria acontecer durante a defecação (Hedlund, 2008), assim a constipação 
pode estar associada à etiologia da saculite no caso em questão.

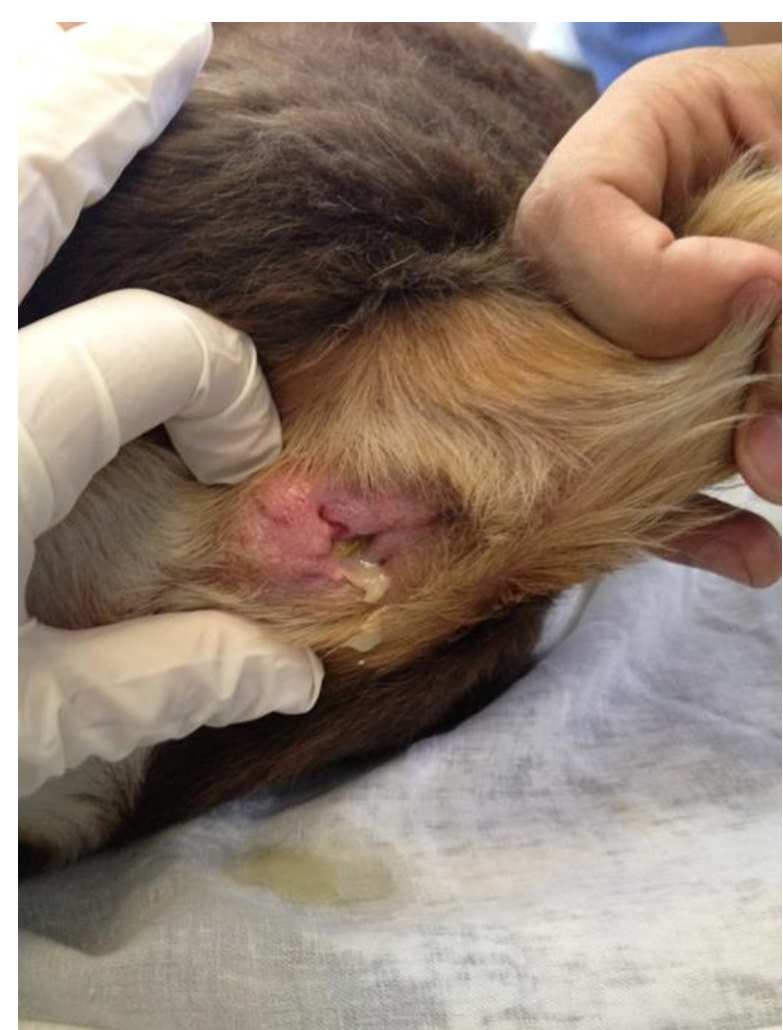

Figura 1. Compressão manual dos sacos anais em animal com saculite.

$\mathrm{O}$ resultado do hemograma indicou que havia uma infecção local, havendo uma boa resposta do hospedeiro (Lopes et al., 2007).

O diagnóstico de saculite foi baseado nos sinais clínicos apresentados pelo animal, bem como, pelas características do conteúdo dos sacos anais, semelhantes aos encontrados por outros autores (Costa Neto et al., 2007).

Existem algumas bactérias que são mais encontradas em casos de saculite anal. Em estudo onde se avaliou o conteúdo de sacos anais em animais com saculite, observou-se que $80 \%$ das bactérias eram do gênero Proteus (Halnan, 1976). Não é do conhecimento dos autores relato onde tenha crescido Klebisiella spp. e Salmonella spp. a partir do conteúdo dos sacos anais, assim acredita-se que essas bactérias estejam intimamente relacionadas com a etiologia da saculite.

A realização de cultura e antibiograma é de extrema importância em casos de saculite (Hedlund, 2008) para que seja realizado um tratamento adequado, diminuindo o risco de recidivas, que são comuns nesses casos (Tirgari, 1988; Matthiesen and Marretta, 1998). O tratamento foi baseado no resultado do antibiograma, além de ser realizada a compressão dos sacos anais, que é de grande relevância no tratamento dessa afecção (Nelson and Couto, 2006). Além disso, a utilização de pomada contendo corticosteroide e antibiótico é um método de tratamento efetivo para casos de saculites em grau leve (Aronson, 2007). Utilizouse antibioticoterapia sistêmica devido à leucocitose que também pode indicar uma infecção generalizada (Lopes et al., 2007).

\section{Conclusão}

Este relato registra um caso de saculite em um cão adulto com hipotireoidismo, que se originou devido à constipação que é um dos sinais clínicos desta endocrinopatia. A adequada anamnese e exame clínico nesse caso foram de extrema importância para que se chegasse ao correto diagnóstico e à instituição de um tratamento adequado.

\section{Referências Bibliográficas}

Aronson, L. 2007. Reto e Ânus. In: Slatter, D. Manual de cirurgia de pequenos animais. $3 \mathrm{ed}$. Manole, São Paulo, São Paulo, Brasil.

Costa Neto, J. M., Menezes, V. P., Nóbrega Neto, P. I., Vieira Júnior, A. S., Toríbio, J. M. M. L., D’Assis \& M. J. M., Teixeira, R. G. 2007. Uso do silicone por condensação para remoção do saco anal em cães. Ceres, 54:291-296.

Halnan, C. R. E. 1976. The diagnosis of anal sacculitis in the dog. Journal of Small Animal Practice, 17:527-535.

Hedlund, C. S. 2008. Cirurgia do sistema digestório. In: Fossum, T. W. Cirurgia de pequenos animais. 3 ed. Elsevier, São Paulo, São Paulo, Brasil.

Lopes, S. T. A., Biondo, A. W. \& Santos, A. P. 2007. Manual de Patologia Clínica Veterinária. UFSM/Departamento de Clínica de Pequenos Animais, Santa Maria, Rio Grande do Sul, Brasil.

Matthiesen, D. T. \& Marretta, S. M. 1998. Afecções do ânus ereto. In: Slatter, D. Manual de cirurgia veterinária de pequenos animais. 2 ed. Manole, São Paulo, São Paulo, Brasil.

Nelson, R. W. \& Couto, C. G. 2006. Medicina interna de pequenos animais. 3 ed. Elsevier, São Paulo, São Paulo, Brasil. 
Panciera, D. L. 1990. Canine hypothyroidism. Part I clinical finding and control of thyroid hormone secretion and metabolism. The Compendium on Continuing Education for the Practicing Veterinarians, 12:689-697.

Tirgari, M. 1988. A simple, clean, method for the surgical ablation of anal sac in dogs. Veterinary Record, 123:365-366.

\section{Article History:}

Received 29 Mayl 2017

Accepted 30 May 2017

Available on line 20 July 2017

License information: This is an open-access article distributed under the terms of the Creative Commons Attribution License 4.0, which permits unrestricted use, distribution, and reproduction in any medium, provided the original work is properly cited 